\title{
Ihlamur Bitkisinin (Tilia cordata) Katı-Sıvı Ekstraksiyonunda Toplam Fenolik Madde Kinetiğinin Matematiksel Modellenmesi
}

\author{
Ahmet Levent iNANÇ ${ }^{1 *}$, Doğanay YÜKSEL ${ }^{1}$ \\ ${ }^{1}$ Kahramanmaraş Sütçü İmam Üniversitesi, Mühendislik-Mimarlık Fakültesi, Gıda Mühendisliği Bölümü, \\ 46040 Kahramanmaraş \\ [ORCID ID: http://orcid.org/0000-0002-7363-5096 (A.L. INANÇ), 0000-0002-1926-5573 (D. YÜKSEL)]. \\ *Sorumlu yazar: linanc@ksu.edu.tr
}

Öz

Ihlamur çayı, en etkili doğal ilaçlardan biridir ve yüzyıllardır kullanılmaktadır. Düzenli olarak tüketildiğinde çeşitli sağıık sorunlarının üstesinden gelinmesinde az veya çok etki gösterebilir. Tilia (Tiliaceae) cinsi bitkilerin gösterdiği antioksidan ve antimikrobiyal aktivite gibi işlevsel özellikler flavonoidler de dahil olmak üzere polifenolik bileşiklerle ilişkilidir. Bu yüzden toplam fenolik bileşiklerce zengin olan ıhlamurun demlenmesinde süre-sıcaklık ilişkisi önemlidir. Bu çalışmada 5 farklı sıcakııkta (60, $70,80,90$ ve $100^{\circ} \mathrm{C}$ ) demlenen ihlamur bitkisinin katı-sIvı ektraksiyonunda polifenollerin sIVI faza geçme süreleri incelenmiştir. Toplam fenolik bileşiklerin katı-sıvı ekstraksiyonunun Matematiksel modellemesinde Fick yasasının uyarlanmış hali kullanılmışır. Ihlamur bitkisinin (Tilia cordata) çayı geleneksel yöntemle hazırlanmıştır. Kuru ıhlamur yaprakları öğütülerek elekten geçirilmiştir. Çelik demleme süzgecine konulan ögütülmüş ıhlamur yaprakları deiyonize su içerisine daldırılmıştır. Homojenize ıhlamur ekstraksiyonu için sabit ve düşük hızda dönen magnetik karıştırıcı kullanılmıştır. Farklı zaman aralıklarında ekstrakt örneği alınmış ve filtre edilmiştir. Ekstraksiyon işlemine her bir sıcaklıktaki ıhlamur konsantrasyonu değişmeyene kadar devam edilmiştir. Örneklerin toplam fenolik bileşikleri spektrofotometrik yöntemle belirlenmiş ve gallik asit eşdeğerleri (GAE) $\mathrm{mg} \mathrm{ml}^{-1}$ olarak ifade edilmiştir. Katı-sıvı faz ıhlamur ekstraksiyon uygulama sonrası bütün sıcaklıklardaki toplam fenolik madde miktarlarının denge konsantrasyonları 40.5-43 $\mathrm{mg} \mathrm{I}^{-1}$ arasında değiştiği belirlenmiştir. Toplam fenolik maddelerin \%99.9' unun sıvı faza transfer süreleri ise yaklaşık 2078-57 dakika arasındadır. En düşük hız sabiti $60^{\circ} \mathrm{C}^{\prime}$ de, en yüksek ise $100^{\circ} \mathrm{C}^{\prime}$ de bulunurken $100^{\circ} \mathrm{C}^{\prime}$ deki hız sabitinin diğer sıcaklıklara göre 2 ile 36 kat daha büyük olduğu gözlemlenmiştir. Ayrıca aktivasyon enerjisi $0.549 \mathrm{~kJ} \mathrm{~g}^{-1}$ olarak belirlenmiştir.

Anahtar Kelimeler: Ihlamur, Fenolik, Ekstraksiyon, Kinetik, Fick Yasası

\section{Mathematical Modeling of Total Polyphenol Compound Kinetics During Solid-Liquid Extraction of Linden (Tilia cordata) Plant}

\begin{abstract}
Linden tea is one of the most effective natural remedies and has been used for centuries. When it is administered regularly, it can help with a wide range of different health issues. Since plants of Tilia (Tiliaceae) genus show both antioxidant and antimicrobial activities, such functional properties are associated with polyphenolic compounds, including flavonoids. Therefore, time-temperature relation is important in the infusion of linden, which is rich in total phenolic compounds. In this study, the transfer times of polyphenols to liquid phase in solid-liquid extraction of linden plants that were brewed at 5 different temperatures $\left(60,70,80,90\right.$ and $\left.100^{\circ} \mathrm{C}\right)$ were investigated. In mathematical modeling, the modified Fick's law was applied. linden plant (Tilia cordata) tea was prepared according to the conventional method. The dry linden leaves were milled and passed through a sieve. The ground linden leaves placed on the steel brewing screen were immersed in deionized water. A constant and low speed rotating magnetic stirrer was used for homogenized linden extraction. the extract sample was
\end{abstract}


withdrawn at different time intervals and filtered. Extraction process was carried out until the extraction concentration at each temperature was not changed. The total phenolic compound of the sample was determined by spectrophotometric method and was expressed as gallic acid equivalents (GAE) mg ml ${ }^{-1}$. It was determined that the equilibrium concentrations of total phenolic substances in liquid phases at all temperatures varied between $40.5-43 \mathrm{mg} \mathrm{l}^{-1}$. The transfer times of $99.9 \%$ of the total phenolic materials to the liquid phases were approximately 2078-57 minutes. The lowest rate constant is found at $60^{\circ} \mathrm{C}$ and the highest at $100^{\circ} \mathrm{C}$, while the rate constant at $100^{\circ} \mathrm{C}$ is 2 to 36 times greater than other temperatures. In addition, the activation energy was determined to be $0.549 \mathrm{~kJ} \mathrm{~g}^{-1}$.

Key Words: Linden, Extraction, Fick's Law, Kinetics, Phenolics

\section{Giriş}

Eczacılıkta bazı preparatlar (ekstre ve şurup gibi) tıbbi bitkilerden hazırlanmaktadır. Bu bitkilerin tıbbi özellikleri dışında değişik amaçlarla kullanıldığı ve bazı sanayi kollarında da hammadde olarak kullanıldığı bilinmektedir. Bu bitkilerin gıda, kozmetik ve parfümeri sanayinin yanında halk ilaçları yapımında kullanımı da mevcuttur. Bununla beraber süs, çevre düzenlemesi ve özellikle de baharat olarak bütün dünyada yaygın bir kullanımı vardır (Usal ve ark., 2001). Bitki çayları hem keyif verici özellikleri hem de sağlık açısından olumlu etkilerinden dolayı günümüzde yaygın olarak tüketilmektedirler. Bitki çaylarının yüksek oranda içerdikleri antioksidan maddelerin (özellikle fenolik bileşikler) insan sağlığı üzerindeki öneminin ortaya çıkması sonucunda bu ürünlerin tüketimi her geçen gün daha da artmaktadır (Ivanova ve ark., 2005). Bu yüzden çaylar ve bitkisel infüzyonlar günlük diyetimizin temel fenolik bileşik kaynaklarını oluşturmaktadır (Atoui ve ark., 2005). Ihlamur değişik Tilia türlerinin kurutulmuş çiçekleridir. İdrar arttırıcı, terletici, yatıştırıcı, göğüs yumuşatıcı etkileri bulunmaktadır ve özellikle infüzyon halinde kullanılmaktadır (Baytop ve ark., 1999). Ihlamur bitkisinin (Tilia) farklı türleri yetiştikleri coğrafi bölgelere bağlı olarak değişiklik gösterebilir. Tilia, türü ne olursa olsun veya orijinal konumu ne olursa olsun, terapötik ve kozmetik özelliklere sahiptir. (Viola ve ark., 1994; Daniel, 1998; Schmidgall ve ark., 2000; Yıldırım ve ark., 2000; Toker ve ark., 2001,2004; Matsuda ve ark., 2002). Ihlamur (Tilia) bitkisi; şeker, yağ, kateşin ve gallik asit, tanin, polifenolik bileşikler, organik asit, mineral tuz, amino asit, vitamin ve uçucu yağ gibi birçok farklı molekül içerir. Bu moleküller bitkiden ekstraksiyon yöntemi ile ayrılabilir. Katı-sıvı faz ekstraksiyonunda, katı maddenin bir kısmı inert olarak kabul edilir ve çözücüde çözünmez (Baser ve ark., 1999). Bununla birlikte bitkinin doğal yapısı, kütle transfer kinetiğini değiştirebilir. Bitkisel hammaddenin katısıvı ekstraksiyonu çok bileşenli, çok fazlı ve yatışkın olmayan bir kütle transfer olayıdır (Tosun ve ark., 2010). Birden çok kimyasal çeşidin katıdan sıvıya transferini içerir. Fick yasasına göre, ekstraksiyon esnasında çözünür bileşenlerin difüzyonu, katı faz (daha konsantre) ile sıvı faz (daha az konsantre) arasında 
mevcut konsantrasyon gradyanına bağlıdır. Bu gradyan, iki faz arasında bir denge kurmak için gelişir (Perry ve ark., 1997) ve daha sonra difüzyon önceden belirlenmiş koşullar altında temas süresi sonsuz uzunlukta olduğunda bile önemsiz hale gelir. Literatürde farklı koşullarda ara yüzey kütle transferini tanımlamak için birçok model bulunmaktadır. Sunulan çoğu örnek film modeline ve penetrasyon modeline dayanmaktadır (Romdhane ve Gourdon, 2002, Mentell ve ark., 2002; Geankoplis ve ark., 2003). Ihlamur bitkisi gibi demlenip içilen bitkisel çaylardaki aktif bileşenlerin demleme sıvısına difüzyonu, kesikli tip solvent ekstraksiyon sistemine göre kinetik modellemesi yapılmaktadır (Chan ve ark., 2014). Bu tip ekstraksiyonda iki aşama bulunur. Birincisi hızlı ekstraksiyon (ıslanma) aşaması ikincisi yavaş ekstraksiyon (difüzyon) aşamasıdır (So ve ark., 1986; Franco ve ark., 2007; Perez ve ark., 2011). Ekstraksiyonun mekanizması, çözücü moleküllerin bitki matrislerine girmesi ve sitoplazma tabakasının direkt olarak çözücüye maruz kalmasıdır (Crossley ve ark., 2001). Bu durum aktif bileşiklerin çözücüye geçmesini kolaylaştırır. Ekstraksiyon işleminin başlangıcındaki hızı aşama, sabit bir ekstraksiyon oranına karşılık gelir (Rakotondramasy-Rabesiaka ve ark., 2009). Son derece yüksek hızlarda gerçekleşen bu ekstraksiyon aşamasındaki sürecin belirlenmesi zordur. Yavaş ekstraksiyon aşamasında, aktif bileşikler bitki matrislerinin iç kısmından difüze olurlar ve çözücünün içinde çözülürler. Bu aşamada ekstraksiyon verimi büyük ölçüde hızlı ekstraksiyon aşaması sonrasında çözücünün temas etmediği hücrelere bağlıdır. Aslında ekstraksiyondaki yavaş ve hızlı aşamaların özellikleri, öğütme gibi örnek hazırlama işleminden sonra ortaya çıkan kesilmiş ve parçalanmamış hücrelerin oranları ile belirlenebilir (So ve ark., 1986). Çözücünün bitki yapısına nüfuzunu arttırmak ve çözücü içerisine bileşenlerin emilimini iyileştirmek için örneğin öğütülmesi yaygın olarak uygulanmaktadır (Gujar ve ark., 2010; Tsibranska ve ark., 2011). Bu çalışmada Ihlamur bitkisinin (Tilia cordata) içermiş olduğu toplam fenolik bileşiklerinin klasik bitkisel çay demleme yöntemi ile ekstraksiyonu yapılmıştır. Sıcaklık ve sürenin toplam fenolik madde (gallik asit cinsinden) ekstraksiyon kinetiğine etkileri incelenmiştir. Fick yasasının analitik çözümü kullanılarak ıhlamur bitkisindeki toplam fenolik bileşiklerin katı-sıvı ekstraksiyonundaki etkin difüzyon (De) katsayıları ve aktivasyon enerjisi bulunmuştur.

\section{Materyal ve Metot}

\section{Materyal}

Çalışmada kullanılan ıhlamur bitkisi (Tilia cordata) yerel bir aktardan temin edildi. Ihlamur yaprakları mikserde öğütüldükten sonra kullanılıncaya kadar +4 ${ }^{\circ} \mathrm{C}^{\prime}$ de muhafaza edildi. FolinCioacalteu reaktifi Merck (İstanbul)'den ve $\mathrm{Na}_{2} \mathrm{CO}_{3}$ Sigma-Aldrich ('istanbul)' den temin edilmiştir. 
Katı-sIVı Faz Ekstraksiyonu

Ihlamur yaprakları (Tilia cordata) mikserde öğütülerek $3 \mathrm{~mm}$ 'lik elekten geçirilmiştir. Her bir sıcaklık $(60,70,80$, 90 ve $100{ }^{\circ} \mathrm{C}$ ) uygulaması için $5 \mathrm{~g}$ öğütülmüş ıhlamur kullanılmıştır. Çelik süzgece konan örnek 1 litre saf su içerisine askıda kalacak şekilde daldırımıştır. Düşük hızda manyetik bir karıştırıcı ile ekstrakt sıvısının homojenizasyonu sağlanmıştır. Belirli dakikalarda pipetle beherden $5 \mathrm{ml}$ örnek alınmıştır. Örnekler filtre kâğıdı (Whatman no:1) ile filtre edildikten sonra ağızları hava almayacak şekilde parafilmle kapatılmıştır. Ihlamur ekstrakları analiz edilinceye kadar +4 ${ }^{\circ} \mathrm{C}^{\prime}$ de depolanmıştır.

Toplam Polifenol Tayini

Toplam polifenol miktarı FolinCiocalteu yöntemine göre spektrofotometrede (Pg Instruments Ltd., model T70+ UV-VIS) ölçüldü. +4 'C'de bekletilen ekstraklar 15-20 dakika oda sıcaklığında bekletilmiştir. Ihlamur ekstraktından cam tüplere $1.5 \mathrm{ml}$ aktarılmış ve $1.5 \mathrm{ml}$ (5 kat saf su ile seyreltilmiş) Folin-Ciocalteu reaktifi ile karıştırılmıştır. 10 dakika sonra $3 \mathrm{ml}$ (\%35'lik) doymuş sodyum karbonat çözeltisi eklenmiş ve 15 saniye boyunca vortekslenmiştir. 45 dakika karanlıkta bekletildikten sonra çözeltinin absorbansı $750 \mathrm{~nm}$ dalgaboyunda ölçülmüştür. Spektrofotometrede okunan absorbans değerleri, gallik asitin 10 ve $100 \mathrm{~g} \mathrm{l}^{-1}$ konsantrasyonlarda hazırlanan kalibrasyon eğrisinden $\quad\left(R^{2}=0.999\right)$ faydalanarak "g gallik asit $\mathrm{I}^{-1 \text { " }}$ olarak hesaplanmıştır (Şekil 1). Analizler 3 tekerrürlü olarak gerçekleştirilmiştir.

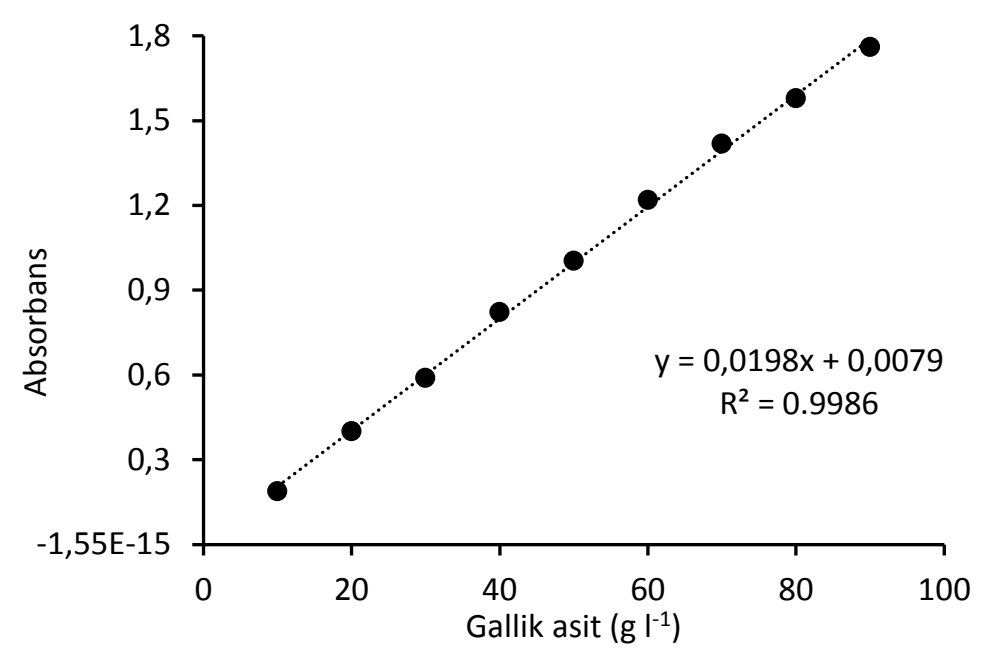

Şekil 1. Gallik asit kalibrasyon eğrisi

Figure 1.Calibration curve of gallic acid

\section{Matematiksel Model}

Hacim sınırlaması olmayan sabit konsantrasyonlu homojen bir ortamda asılı halde bulunan küresel parçacıkların durağan olmayan davranışları için Fick yasasının uyarlanmış hali kullanılmıştır. 
Fick eşitliğinin çözümü aşağıda açılanmıştır (Perez ve ark., 2011).

$\frac{M_{t}}{M_{\infty}}=1-\sum_{n-1}^{\infty} A_{n} \exp \left(-B_{n} t\right)$

Burada;

$t$ : difüzyon süresi ( $\mathrm{dk})$,

$M_{t}$ : herhangi bir $t$ difüzyon süresindeki toplam fenol madde miktarı (g gallik asit $\mathrm{I}^{-1}$ )

$M_{\infty}: t_{\infty}$ (denge) noktasındaki toplam fenol madde miktarı (g gallik asit $\mathrm{I}^{-1}$ )

$t=0 \quad M=0$

$t=t_{0} \quad M=M_{0}$

$t=t \quad M=M_{t}$

$t \rightarrow \infty \quad M=M_{\infty}$

Yukarıdaki şartlar göz önünde bulundurulduğunda eşitlik (1)

$\frac{M_{t}}{M_{\infty}}=1-\left(1-\frac{M_{0}}{M_{\infty}}\right) \sum_{n-1}^{\infty} A_{n} \exp \left[-B_{n}\left(t-t_{0}\right)\right]$

şeklinde ifade edilebilir.

Madde miktarındaki değişim yeterince uzun süreler göz önüne alındığında eşitlik (6)

$\frac{M_{t}}{M_{\infty}}=1-A \exp (-B t)$ şeklinde sadeleşebilir.

Burada A ve B model sabitlerini ifade etmektedir. Teorik olarak B değeri aşağıdaki biçimde ifade edilebilir (Chan ve ark., 2014).

$B=\frac{D_{e} \pi^{2}}{R^{2}}$

Aktivasyon enerjisi hesaplanmasında aşağıdaki Arrhenius eşitliği kullanılmıştır.

$D_{e}=D_{0} e^{-\left[\Delta E_{d} / R_{g} T\right]}$

Burada $D_{e}$ etkin difüzyon hız sabiti $\left(\mathrm{m}^{2}\right.$ $\left.\mathrm{dk}^{-1}\right), D_{0}$ Arrhenius sabiti, $\Delta E_{d}$ aktivasyon enerjisi ( $\mathrm{kJ} \mathrm{g}^{-1}$ gallik asit), $\mathrm{R}_{\mathrm{g}}$ gaz sabiti $\left(0.0489 \mathrm{~J}\right.$ (g gallik asit) $\left.{ }^{-1}(\mathrm{~K})^{-1}\right), \mathrm{T}$ mutlak sıcaklık (K) olarak ifade edilmiştir.

\section{Araştırma Bulguları ve Tartışma}

Katı-sıvı faz ıhlamur ekstraksiyon uygulama sonrası bütün sıcaklıklardaki toplam fenolik madde miktarlarının denge konsantrasyonları $\left(M_{\infty}\right)$ 40.5-43 $\mathrm{mg}^{-1}$ arasında bulunmuştur. Herhangi bir zamandaki konsantrasyonun denge konsantrasyonuna oranının ( $\left.M / M_{\infty}\right)$ zamana (t) bağlı değişimleri şekil 2'de verilmiştir. 


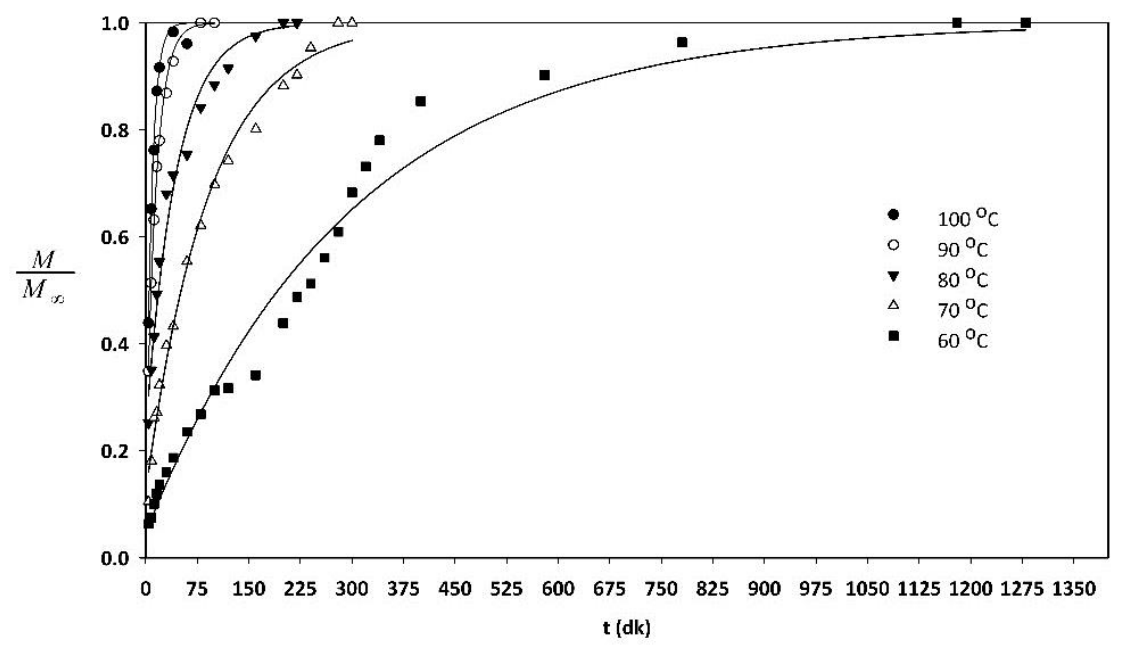

Şekil 2. Herhangi bir zamandaki konsantrasyonun (M) denge konsantrasyonuna $\left(\mathrm{M}_{\infty}\right)$ oranının zamana ( $\mathrm{t}$ ) bağlı değişimleri

Figure 2. Changes of ratio of the concentrations at any time ( $M$ ) to the equilibrium concentrations $\left(M_{\infty}\right)$ with respect to time

Sıcaklığa bağlı deneysel $\mathrm{M} / \mathrm{M}_{\infty}-\mathrm{t}$ software) grafik programı kullanılmıştır. verilerine en uygun ekstraksiyon hı Çizelge $1^{\prime}$ de hı eşitliğinin $A$ ve $B$ eşitliğinin (eşitlik 7) katsayılarını katsayılarının değerleri verilmiştir. belirlemek için Sigmaplot 13 (Systat

1

Çizelge 1. Matematiksel modelin (eşitlik 7) katsayıları Table 1. Coefficients of mathematical model (Equation 7)

\begin{tabular}{ccccccc}
\hline \multirow{2}{*}{$\mathrm{T}\left({ }^{\circ} \mathrm{C}\right)$} & \multicolumn{2}{c}{$\begin{array}{c}\text { Katsayı A } \\
\text { Coefficient } A\end{array}$} & & \multicolumn{2}{c}{$\begin{array}{c}\text { Katsayı B } \\
\text { Coefficient B }\end{array}$} & \multirow{2}{*}{$\mathrm{R}^{2}$} \\
\cline { 2 - 3 } \cline { 5 - 6 } & $\begin{array}{c}\text { Değer } \\
\text { Value }\end{array}$ & $\begin{array}{c}\text { std. Hata } \\
\text { std. Error }\end{array}$ & & $\begin{array}{c}\text { Değer } \\
\text { Value }\end{array}$ & $\begin{array}{c}\text { std. Hata } \\
\text { std. Error }\end{array}$ & \\
\hline 100 & 0.9093 & 0.0525 & & 0.1193 & 0.0078 & 0.9879 \\
90 & 0.8489 & 0.0373 & & 0.0686 & 0.0043 & 0.9896 \\
80 & 0.7632 & 0.0287 & & 0.0226 & 0.0018 & 0.9789 \\
70 & 0.8780 & 0.0171 & & 0.0109 & 0.0005 & 0.9901 \\
60 & 0.9524 & 0.0192 & & 0.0033 & 0.0002 & 0.9781 \\
\hline
\end{tabular}

$\mathrm{Bu}$ katsayıların regresyon belirleme katsayıları $\quad\left(R^{2}\right) \quad 0.9781-0.9901$ aralığındadır. Hız eşitlikleri kullanılarak hesaplanan $60,70,80,90$ ve $100{ }^{\circ} \mathrm{C}$ sıcaklıklardaki toplam fenolik maddelerin \%99.9' unun (M/M⿻0.999) sIvı faza transfer süreleri sırasıyla yaklaşık 2078,
622, 294, 98 ve 57 dakikadır. Eşitlik 9 kullanılarak etkin difüzyon katsayıları $\left(D_{e}\right)$ hesaplanmıştır. Aktivasyon enerjisi ve Arrhenius sabitini $\left(D_{0}\right)$ (eşitlik 9) belirlemek için difüzyon katsayılarının $\left(D_{e}\right)$ sıcaklığın tersine $(1 / T)$ karşı değişim grafiği çizilmiştir (Şekil 3). 


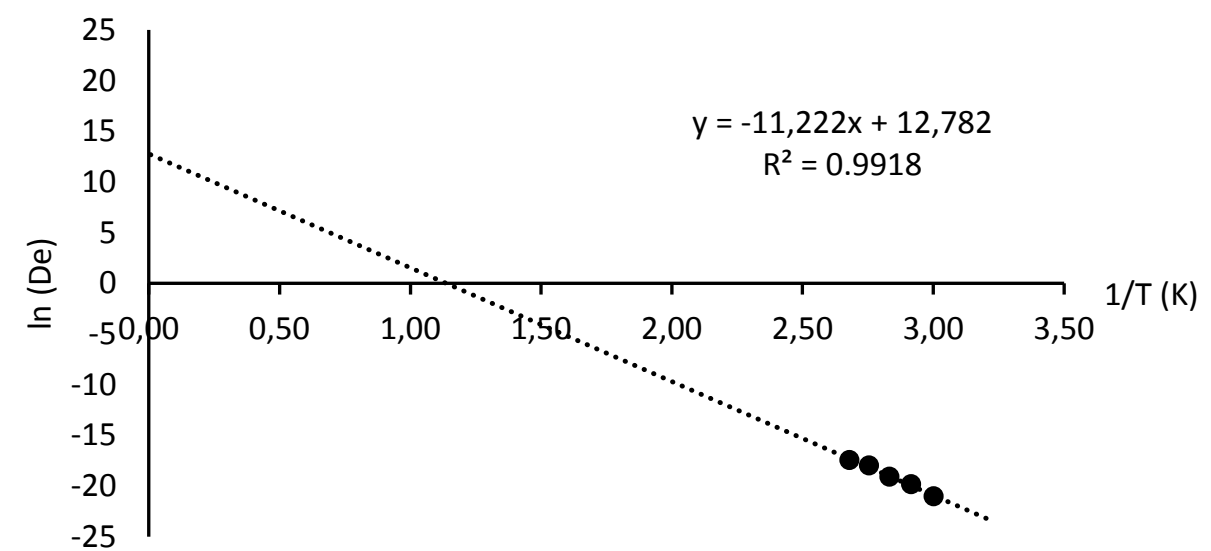

Şekil 3. Difüzyon katsayısının sıcaklığın tersine (1/T) karşı grafiği

Figure 3. Graph of diffusion coefficient versus inverse temperature (1/T)

Hesaplanan Arrhenius parametreleri çizelge 2'de gösterilmiştir. Sıcaklık artıkça difüzyon katsayılarında da artış olmuştur. $100{ }^{\circ} \mathrm{C}^{\prime}$ deki difüzyon katsayısı 90, 80, 70 ve $60^{\circ} \mathrm{C}^{\prime}$ deki difüzyon katsayılarına oranlandığında sırasıyla yaklaşık 2, 5, 11 ve 36 kat daha büyük olduğu belirlenmiştir.

Çizelge 2. Arrhenius parametreleri

Table 2. Arrhenius parameters

\begin{tabular}{cccccc}
\hline $\mathrm{T}\left({ }^{\circ} \mathrm{C}\right)$ & $\mathrm{D}_{\mathrm{e}} \times 10^{-9}$ & & $\mathrm{D}_{\mathrm{o}} \times 10^{5}$ & $\Delta \mathrm{E}_{\mathrm{d}}$ & $\mathrm{R}^{2}$ \\
\cline { 1 - 2 } \cline { 5 - 6 } 100 & 27.22 & & & & \\
90 & 15.65 & & & & \\
80 & 5.16 & & 3.6 & 549 & 0.9918 \\
70 & 2.49 & & & \\
60 & 0.75 & & & \\
\hline
\end{tabular}

\section{Denge konsantrasyonlarına}

bakıldığında ıhlamur yaprağındaki toplam fenolik madde bütün sıcaklıklarda sıvı faza geçmemiştir. Bu durum ekstrakte edilmiş ıhlamur yaprağının sıcaklığı, partikül büyüklüğü veya morfolojik yapısından kaynaklanabilir. Difüzyonda hızlı aşamadan sonra yavaş aşamaya geçilmesi ile katı fazdaki bozulmamış hücrelere sıcaklığın azalması ile de çözücünün ulaşması zorlaşmaktadır

(Crossley ve ark., 2001). HarounaOumarou ve arkadaşları (2007), ıhlamur yaprağındaki toplam kuru maddenin katı fazdan difüzyon yolu ile sıvı faza geçişini incelemişler ve ekstraksiyon hızını ve katsayısını belirlemede birinci ve ikinci mertebe hız eşitliğini karşılaştırmışlardır. Yalancı 2. mertebeden hız eşitliğinin uygun eşitlik olduğunu bildirmişlerdir. Fakat bu çalışmada bulunan difüzyon katsayıları ile karşılaştırıldığında oldukça farklı sonuçlar çıkmıştır. Farklı bitkisel çaylarda (beyaz çay gibi) sıcaklık artışı ile birlikte katı fazdaki kateşin, kafein vb. fenolik grubuna dahil maddelerin sivı faza geçişlerindeki artışı daha önceki araştırmacılar da bildirmiştir (Cacace ve ark., 2003; Cissé ve ark., 2012; Lin ve ark., 2017). Sıcaklık ekstrakte edilecek bitkinin hücre duvarını parçalamasıyla ekstraksiyon hızına olumlu etki 
etmektedir (Pinelo ve ark., 2006; Haldar ve ark., 2015).

\section{Sonuçlar}

Ihlamurun geçmişten günümüze kadar bitki çayı tüketimi bakımından önemli bir yeri olmuştur. Bu bitkinin insan sağlığı üzerine olumlu etkilerinin ortaya çıkmasıyla günümüzde ilgi daha fazla artmaktadır. Bitkinin içerdiği toplam fenolik bileşikler önemli maddelerdir. Bu yüzden ıhlamur bitkisi çayının konveksiyonel demleme işlemi gerçekleştirilmiş, toplam fenolik bileşiklerin katı-sıvı faz ekstraksiyonunda Fick yasasından türetilen ekstraksiyon eşitliği kullanılarak farklı sıcaklıklardaki difüzyon katsayıları belirlenmiştir. Sıcaklık artışıyla difüzyon katsayılarında da artış gözlenmiştir. Uygulanan sıcaklıklar arasındaki farkların 2 ila 36 kat arasında olduğu belirlenmiştir. Aktivasyon enerjisi de $0.549 \quad \mathrm{~kJ}^{-1}$ bulunmuştur. Hesaplanan bu aktivasyon enerjisi oldukça düşüktür. Demleme işleminin en fazla 20-25 dakikaya kadar $100{ }^{\circ} \mathrm{C}$ sıcaklıkta yapılması hızlı ekstraksiyon için tavsiye edilebilir; daha sonra bu sıcaklıkta sabit tutulmayıp sıcaklığın düşürülmesi daha uygun bir işlem olacaktır. Çünkü teorik olarak yüksek sıcaklıklarda bozulma tepkimeleri gerçekleşebilir. Ideal demleme sıcaklığının $80-90{ }^{\circ} \mathrm{C}$ arasında olması daha uygun görünmektedir. $60-70{ }^{\circ} \mathrm{C}$ arasında sıcaklık uygulaması ekstraksiyon hızını önemli ölçüde yavaşlattığından demleme işlemi için uygun görünmemektedir.

\section{Kaynaklar}

Atoui, A.K., Mansouri, A., Boskou, G., Kefalas, P., 2005. Tea and Herbal Infusions: Their Antioxidant Activity and Phenolic Profile. Food Chemistry, 89: 27-36.

Baser, K., Kürkçüoğlu, M., Özek, T., 1999. The Composition of Essential Oils From Tilia L. Species Growing in Turkey. Journal of Essential Oil Research, 11: 369-374.

Baytop, T., 1999. Türkiye'de Bitkiler ile Tedavi: Geçmişte ve Bugün (ilaveli 2. Baskı). Nobel Tıp Kitapları, İstanbul, 480s.

Cacace, J. E., Mazza, G., 2003. Mass Transfer Process During Extraction of Phenolic Compounds from Milled Berries. Journal of Food Engineering, 59 (4): 379-389.

Chan, C.H., Yusoff, R., Ngoh, G.C., 2014. Modeling and Kinetics Study of Conventional and Assisted Batch Solvent Extraction. Chemical Engineering Research and Design, 9 (2): 1169-1186.

Cisse, M., Bohuon, P., Sambe, F., Kane, C., Sakho, M., Dornier, M., 2012. Aqueous Extraction of Anthocyanins from Hibiscus sabdariffa: Experimental Kinetics and Modeling. Journal of Food Engineering, 109: 16-21.

Crossley, J.I., Aguilera, J.M., 2001. Modeling The Effect of Microstructure on Food Extraction. Journal of Food Process Engineering, 24: 161-177.

Daniel, A., 1998. Preparation lavante a usage capillaire. French Patent, FR2752730.

Franco, D., Sineiro, J., Pinelo, M., Núñez,M.J., 2007. Ethanolic Extraction of Rosa rubiginosa Soluble Substances: Oil Solubility Equilibria and Kinetic Studies. Journal of Food Engineering, 79: 150-157.

Geankoplis, C.J., 2003. Transport Processes and Separation Process Princeples: Includes Unite Operations (4. Baskı). Prentice Hall. New Jersey, 410-490.

Gujar, J.G., Wagh, S.J., Gaikar, V.G., 2010. Experimental and Modeling Studies on Microwave-assisted Extraction of Thymol From Seeds of Trachyspermum ammi (TA). Separation and Purification Technology, 70 (3): 257-264.

Haldar, S., Majumdar, G.C., Mishra, H.N., 2015. Modeling the Kinetics of Extracting Oleoresin from Dried Turmeric (Curcuma longa L.) Rhizome Using Acetone as Solvent. Journal of Food Engineering, 146: 116-121. 
Harouna-Oumarou, H.A., Fauduet, H., Porte, C., Ho, Y., 2007. Comparison of Kinetic Models for the Aqueous Solid-Liquid Extraction of Tilia Sapwood in a Continuous Stirred Tank Reactor. Chemical Engineering Communications, 194: 537552.

Ivanova, D., Gerova, D., Chervenkov, T., Yankova, T., 2005. Polyphenols and Antioxidant Capacity of Bulgarian Medicinal Plants. Journal of Ethnopharmacology, 96: 145150.

Lin, C., Xia, G., Liu, S., 2017. Modelling and Comparison of Extraction Kinetics of 8 Catechins, Gallic Acid and Caffeine from Representative White Teas. LWT - Food Science and Technology, 83: 1-9.

Matsuda, H., Ninomiya, K., Shimoda, H., Yoshikawa, M., 2002. Hepatoprotective Principles from the Flowers of Tilia argentea (Linden): Structure Requirements of Tiliroside and Mechanisms of Action. Bioorganic \& Medicinal Chemistry, 10: 707-712.

Mentell, C., Rodriguez, M., 2002. Semi-Batch Extraction of Anthociyanins from Red Grape Pomace in Packed Beds: Experimental Results and Process Modelling. Chemical Engieering Science, 57: 3831-3838.

Perez, E.E., Carelli, A.A., Crapiste, G.H., 2011. Temperature-dependent Diffusion Coefficient of Oil from Different Sunflower Seeds During Extraction with Hexane. Journal of Food Engineering, 105: 180185.

Perry, R., Green, D.W., Maloney, J.O., 1997. Perry's Chemical Engineers' Handbook (7. Baskı). McGraw-Hill, New York, 2640s.

Pinelo, M., Arnous, A., Meyer, A.S., 2006. Upgrading of Grape Skins: Significance of Plant Cell-wall Structural Components and Extraction Techniques for Phenol Release. Trends in Food Science \& Technology, 17 (11): 579-590.

Rakotondramasy-Rabesiaka, L., Havet, J.L., Porte, C., Fauduet, H., 2009. Solid-liquid Extraction of Protopine from Fumaria officinalis L. - Kinetic Modelling of Influential Parameters. Industrial Crops ans Products, 29 (2-3): 516-523.
Romdhane, M., Gourdon, C., 2002. Investigation in Solid-liquid Extraction: Influence of Ultrasound. Chemical Engineering Journal, 87: 11-19.

Schmidgall, J., Schnetz, E., Hensel, A., 2000. Evidence for Bioadhesive Effects of Polysaccharides and Polysaccharidecontaining Herbs in an ex vivo Bioadhesion Assay on Buccal Membranes. Planta Medica, 66: 48-53.

So, G.C., Macdonald, D.G., 1986. Kinetics of Oil Extraction from Canola (Rapeseed). The Canadian Journal of Chemical Engineering, 64: 80-86.

Toker, G., Aslan, M., Yeşilada, E., Memişoğlu, M., Ito, S., 2001. Comparative Evaluation of the Flavonoid Content in Officinal Tiliae flos and Turkish Lime Species for Quality Assessment. Journal of Pharmaceutical and Biomedical Analysis, 26: 111-121.

Toker, G., Küpeli, E., Memişoğlu, M., Yeşilada, E., 2004. Flavonoids with Anti-nociceptive and Anti-inflammatory Activities from the Leaves of Tilia argentea (silver linden). Journal of Ethnopharmacology, 95 (2-3): 393-397.

Tosun, G., Bozan, B., 2010. Üzüm Çekirdeğinden Fenolik Bileşiklerin Ekstraksiyonu ve Kütle Transfer Parametrelerinin Incelenmesi. 9. Ulusal Kimya Mühendisliği Kongresi, 22-25 Haziran, Ankara.

Tsibranska, I., Tylkowski, B., Kochanov, R., Alipieva, K., 2011. Extraction of Biologically Active Compounds From Sideritis ssp. L. Food Bioproducts Processing, 89 (4): 273280.

Usal, G., Özde A.A., 2001. Türkiye'nin Tıbbi Bitkiler Ihracat Potansiyeli. Gıda, 10: 7879.

Viola, H., Wolfman, C., Levi de Stein, M., Wasowski, C., 1994. Isolation of Pharmacologically Active Benzodiazepine Receptor Ligands from Tilia tomentosa (Tiliaceae). Journal of Ethnopharmacology, 44: 47-53.

Yıldırım, A., Mavi, A., Oktay, M., Kara, A.A., Algur, O.F., Bilaloğlu, V., 2000. Comparison of Antioxidant and Antimicrobial Activities of Tilia (Tilia argenta Desf Ex DC), Sage (Salvia triloba L.) and Black Tea (Camellia sinensis) Extracts. Journal of Agricultural and Food Chemistry, 48: 5030-5034. 